\title{
Effect of Therapeutic and Double Therapeutic Doses of Ivermectin on Oxidative Status and Reproductive Hormones in Male Rabbits
}

\begin{abstract}
Ali Hafez El-Far
Department of Biochemistry, Faculty of Veterinary Medicine, Damanhour University, Egypt

Received 2013-07-10, Revised 2013-08-23; Accepted 2013-08-27

ABSTRACT

To investigate the biochemical alterations of oxidative status and male sexual hormones, thyroid hormones, cortisol, liver function and kidney function; sixty male New Zealand White rabbits were equally allotted according to their body weight into two groups. Control samples were collected before subcutaneous injection of rabbits by ivermectinin Therapeutic (TD) and Double Therapeutic Doses (DTD). After injection blood samples were collected from ear vein at $1^{\text {st }}, 3^{\text {rd }}$ and $7^{\text {th }}$ day of experiment and subjected to the biochemical analysis of urea, uric acid, creatinine, aspartate transaminase, alanine transaminase, lactate dehydrogenase, creatine phosphokinase, triiodothyronine, thyroxin, nitric oxide, total antioxidant capacity, cortisol, testosterone and free testosterone. The obtained data of both TD and DTD revealed a significant increase in urea, uric acid, creatinine, aspartate transaminase, alanine transaminase, lactate dehydrogenase, creatine phosphokinase, triiodothyronine, thyroxin, nitric oxide, cortisol, testosterone and free testosterone while total antioxidant capacity levels were significantly decreased. From the date data of the current study on TD and DTD with a higher value in the DTD. We can conclude that ivermectin induced deleterious effects on kidneys and hepatic functions, oxidative stress, weight loss and increased testosterone and free testosterone.
\end{abstract}

Keywords: Ivermectin, Oxidative Stress, Testosterone, Free Testosterone

\section{INTRODUCTION}

Helmint infestations had been a persistent and major constraint on the performance and reproduction of the domestic animals. These infestations are chronic and debilitating in their effect causing huge economic losses. Therefore, the farmers are mainly depending on anthelmintics for helmint control (Godara et al., 2011). Eight naturally occurring novel macro cyclic lactones, namely Avermectin (AVMs); $A_{1 a}, A_{1 b}, A_{2 a}, A_{2 b}, B_{1 a}, B_{1 b}$, $\mathrm{B}_{2 \mathrm{a}}, \mathrm{B}_{2 \mathrm{~b}}$ had been discovered (Awasthi et al., 2012). Five AVMs namely Abamectin (ABM), Ivermectin (IVM), Eprinomectin (EPR), Doramectin (DOR) and Emamectin (EMA) are widely as treatment of a broad spectrum of parasitic diseases (Giannetti et al., 2011). IVM is a mixture of two chemically modified avermectins that contain at least $80 \%$ of 22,23 -dihydroavermectin- $\mathrm{B}_{1 \mathrm{a}}$ and $20 \%$ of $22,23-$ dihydroavermectin- $\mathrm{B}_{1 \mathrm{~b}}$ (Lumaret et al., 2012). IVM is one of the most effective and widely used antiparasitic agents of broad-spectrum activity against numerous endoparasites and ectoparasites, especially nematodes and arthropods (Chaccour et al., 2013). However, IVM exhibits a broad spectrum of activity against gastrointestinal and lung nematodes as well as against ectoparasites of clinical relevance in domestic animals (Suarez et al., 2013). The anthelmintic effect of IVM induced by inhibition of pharyngeal pumping by glutamate. In addition, paralysis of somatic muscles is associated with GABA-gated chloride channel receptors (Yovany et al., 2010).

AVMs overdose could cause a combination of clinical side effects ranging from mild to extremely severe (Epstein and Hollingsworth, 2013). The most dominant clinical symptoms of IVM poisoning in domestic and wild animals are CNS depression and sometimes coma, frequently resulting in death (Trailovic and Nedeljkovic, 2011). The central and peripheral GABA ergic properties 
were involved in IVM toxicity in mammals and indicate involvement of the cholinergic system in its toxicity (Trailovic and Nedeljkovic, 2011). In addition to the neural effects of IVM, it but has marked effects on some liver function enzymes such as Aspartate Transaminase (AST; EC 2.6.1.1), Alanine Transaminase (ALT; EC 2.6.1.2) and $\gamma$-glutamyltranspeptidase (GGT; EC 2.3.2.2) at therapeutic and toxic doses of IVM to albino rats (Ashang, 2009).

The current study aimed to investigate the biochemical alterations of oxidative status, male sexual hormones, thyroid hormones, cortisol, liver function and kidney function; sixty male New Zealand White rabbits biochemical alterations of oxidative status and male sexual hormones in male New Zealand White rabbits injected subcutaneously by the therapeutic and double therapeutic doses of IVM by measurement of serum urea, uric acid, creatinine, aspartate transaminase (AST; EC 2.6.1.1), alanine transaminase (ALT; EC 2.6.1.2), lactate dehydrogenase (LDH; $\quad \mathrm{EC}$ 1.1.1.27), creatine phosphokinase (CPK; EC 2.7.3.2), triiodothyronine $\left(\mathrm{T}_{3}\right)$, thyroxin $\left(\mathrm{T}_{4}\right)$, nitric oxide $(\mathrm{NO})$, total antioxidant capacity (TAC), cortisol, testosterone and free testosterone.

\section{MATERIAL AND METHODS}

\subsection{Experimental animals}

Sixty New Zealand White male rabbits of ten months of age weighting about $6-7 \mathrm{~kg}$ were used for the present study. They were housed in clean polypropylene cages and maintained under standard laboratory conditions at an ambient temperature of $25 \pm 2^{\circ} \mathrm{C}$ with $55-64 \%$ relative humidity and a $12 \mathrm{~h}$ light dark cycle. They were allowed free access to a standard pellet diet and water $a d$ lib. Rabbits were kept under the same hygienic and environmental conditions during the experimental period.

\subsection{Experimental Design}

The study was conducted in Al-Bostan farm of the Faculty of Veterinary Medicine, Damanhour University, on sixty male New Zealand White rabbits that were allocated according to their initial live body weight into two equal groups of thirty in each. The Therapeutic Dose (TD) group, were injected subcutaneously by $0.5 \mathrm{mg} \mathrm{kg}^{-1}$ and the Double Therapeutic Dose (DTD) group were injected with $1 \mathrm{mg} \mathrm{kg}^{-1}$ of IVM via subcutaneous injection (Atakisi et al., 2009). Blood samples were collected before the injection of IVM as control while the samples were collected at $1^{\text {st }}, 3^{\text {rd }}$ and $7^{\text {th }}$ days after injection of IVM.

\subsection{Biochemical Analysis}

All blood samples of $3 \mathrm{~mL}$ were collected from the ear vein at times immediately before injection of IVM as control and on $1^{\text {st }}, 3^{\text {rd }}$ and $7^{\text {th }}$ day of medication. Blood samples were centrifuged at 3000 r.p.m. for $10 \mathrm{~min}$ to separate a clear serum. Collected serum samples were subjected to biochemical analysis of urea, uric acid, creatinine, AST, ALT and LDH. All biochemical parameters were analyzed by commercially available kit methods. UNICO 2100 UV-Spectrophotometers, ELx800 Absorbance Microplate Reader and other laboratory equipment aids were used for biochemical analysis. Moreover, each parameter was done according to the instructions of its kit.

\subsection{Statistical Analysis}

The descriptive data are presented as the means $\pm \mathrm{SE}$. The statistical differences were calculated based on two way test of ANOVA and $\mathrm{p}<0.05$ is considered as significant between the groups.

\section{RESULTS}

The data presented in Table $\mathbf{1}$ showed that subcutaneous injection of IVM significantly $(p<0.05)$ increased the serum levels of urea and uric acid in male rabbits in both TD and DTD groups with the highest effect on the $3^{\text {rd }}$ day as compared with control samples (urea; $62.67 \pm 4.70$ and $77.00 \pm 5.20$ Vs. $31.67 \pm 3.18$ ) and (uric; $8.57 \pm 0.94$ and $9.01 \pm 0.11$ Vs. $6.31 \pm 0.17$ ), respectively.

The data illustrated in Table 1 recorded a significant $(p<0.05)$ increase in creatinine level in the DTD group in comparison to control samples at $3^{\text {rd }}$ and $7^{\text {th }}$ day. Moreover, its level of TD group and $1^{\text {st }}$ day in DTD group were non-significantly increased.

The obtained data in Table 1 stated a significant $(\mathrm{p}<0.05)$ gradually increase in AST and ALT enzyme activities with time in a TD group while, their levels were significantly increased at $1^{\text {st }}, 3^{\text {rd }}$ and $7^{\text {th }}$ day in DTD comparably with control samples.

In addition, in DTD group the levels of LDH and CPK were significantly $(p<0.05)$ increased in DTD group when compared with that of control samples. Concerning to their levels in the TD group were nonsignificantly increased (Table 2). The serum concentrations of $\mathrm{T}_{3}$ and $\mathrm{T}_{4}$ were significantly increased in gradual manner with time at $1^{\text {st }}, 3^{\text {rd }}$ and $7^{\text {th }}$ day in TD and DTD groups Table 2. 
The data illustrated in Table 3 showed a significant $(\mathrm{p}<0.05)$ increase in serum cortisol levels at $3^{\text {rd }}$ and $7^{\text {th }}$ day after IVM injection in DTD group. Whilst, its increase in TD group and $1^{\text {st }}$ day in DTD groups were non-significant in relation to group one. The obtained data in Table 3 recorded a significant gradual decrease in the level of serum TAC during the course of the experiment in both TD and DTD groups in comparison to control samples. On the contrary, the levels of NO were significant gradually increased with the experimental time in those groups.
The data recorded in Table 4 revealed that in TD group serum testosterone concentrations were significantly $(p<0.05)$ increased at $7^{\text {th }}$ day. In addition, its concentrations in DTD were significantly $(p<0.05)$ increased on $1^{\text {st }}, 3^{\text {rd }}$ and $7^{\text {th }}$ day of the experiment $(2.70 \pm 0.43,2.74 \pm 0.04$ and $2.94 \pm 0.03$, respectively). In the same context, the serum free testosterone concentrations were significantly increased in both TD and DTD at $1^{\text {st }}, 3^{\text {rd }}$ and $7^{\text {th }}$ day with the highest levels at $3^{\text {rd }}$ day $(92.86 \pm 1.15)$ and $7^{\text {th }}$ day $(86.14 \pm 1.38)$ in DTD group.

Table 1. The mean values of urea $(\mathrm{mg} / \mathrm{dL})$, uric acid $(\mathrm{mg} / \mathrm{dL})$, creatinine $(\mathrm{mg} / \mathrm{dL})$, ALT (U/L), AST (U/L), LDH (U/L) and CPK (U/L) in control samples, Therapeutic Dose (TD) and Double Therapeutic Dose (DTD) groups.

\begin{tabular}{|c|c|c|c|c|c|c|}
\hline & & Urea & Uric acid & Creatinine & ALT & AST \\
\hline Control & & $31.67 \pm 3.18^{\mathrm{b}}$ & $6.31 \pm 0.17^{b}$ & $0.46 \pm 0.11^{\mathrm{b}}$ & $45.67 \pm 2.91^{\mathrm{c}}$ & $103.33 \pm 4.10^{\mathrm{d}}$ \\
\hline \multirow[t]{3}{*}{$\mathrm{TD}$} & $1^{\text {st }}$ day & $60.67 \pm 5.24^{\mathrm{a}}$ & $8.15 \pm 0.09^{\mathrm{a}}$ & $0.64 \pm 0.04^{\mathrm{b}}$ & $73.67 \pm 4.10^{\mathrm{b}}$ & $143.67 \pm 9.94^{\mathrm{c}}$ \\
\hline & $3^{\text {rd }}$ day & $62.67 \pm 4.70^{\mathrm{a}}$ & $8.57 \pm 0.94^{\mathrm{a}}$ & $0.72 \pm 0.12^{\mathrm{b}}$ & $84.00 \pm 4.73^{\mathrm{a}}$ & $158.00 \pm 3.51^{\mathrm{c}}$ \\
\hline & $7^{\text {th }}$ day & $60.67 \pm 5.24^{\mathrm{a}}$ & $8.04 \pm 0.51^{\mathrm{a}}$ & $0.73 \pm 0.1^{\mathrm{b}}$ & $93.00 \pm 4.16^{\mathrm{a}}$ & $170.33 \pm 5.81^{b c}$ \\
\hline \multirow[t]{3}{*}{ DTD } & $1^{\text {st }}$ day & $67.67 \pm 8.45^{\mathrm{a}}$ & $8.48 \pm 0.48^{\mathrm{a}}$ & $0.61 \pm 0.08^{\mathrm{b}}$ & $99.00 \pm 7.57^{\mathrm{a}}$ & $269.00 \pm 17.35^{\mathrm{a}}$ \\
\hline & $3^{\text {rd }}$ day & $77.00 \pm 5.20^{\mathrm{a}}$ & $9.01 \pm 0.11^{\mathrm{a}}$ & $0.97 \pm 0.4^{\mathrm{a}}$ & $96.00 \pm 2.89^{\mathrm{a}}$ & $264.33 \pm 8.82^{\mathrm{a}}$ \\
\hline & $7^{\text {th }}$ day & $70.67 \pm 6.44^{\mathrm{a}}$ & $8.70 \pm 0.38^{\mathrm{a}}$ & $0.87 \pm 0.04^{\mathrm{ab}}$ & $84.67 \pm 4.1^{\mathrm{ab}}$ & $195.00 \pm 9.17^{\mathrm{b}}$ \\
\hline
\end{tabular}

Values are expressed as means \pm SE; Means within the same column carrying different letters are significantly different at ( $<<0.05$ )

Table 2. The mean values of $\mathrm{LDH}(\mathrm{U} / \mathrm{L}), \mathrm{CPK}(\mathrm{U} / \mathrm{L}), \mathrm{T}_{3}(\mathrm{ng} / \mathrm{mL})$ and $\mathrm{T}_{4}(\mathrm{ug} / \mathrm{dL})$ in control samples, Therapeutic Dose (TD) and Double Therapeutic Dose (DTD) groups

\begin{tabular}{llllll}
\hline & & LDH & CPK & $\mathrm{T}_{3}$ & $\mathrm{~T}_{4}$ \\
\hline Control & $104.00 \pm 9.05^{\mathrm{b}}$ & $24.67 \pm 2.19^{\mathrm{b}}$ & $0.77 \pm 0.02^{\mathrm{g}}$ & $2.51 \pm 0.05^{\mathrm{f}}$ \\
TD & $106.57 \pm 9.77^{\mathrm{b}}$ & $30.67 \pm 6.77^{\mathrm{b}}$ & $1.17 \pm 0.11^{\mathrm{f}}$ & $6.03 \pm 0.07^{\mathrm{b}}$ \\
& $1^{\text {st }}$ day & $110.23 \pm 15.51^{\mathrm{b}}$ & $33.00 \pm 0.58^{\mathrm{b}}$ & $1.41 \pm 0.02^{\mathrm{e}}$ & $6.65 \pm 0.05^{\mathrm{d}}$ \\
& $3^{\text {rd }}$ day & $126.23 \pm 8.19^{\mathrm{b}}$ & $31.67 \pm 8.51^{\mathrm{b}}$ & $1.93 \pm 0.03^{\mathrm{d}}$ & $8.22 \pm 0.06^{\mathrm{c}}$ \\
DTD & $7^{\text {th }}$ day & $219.57 \pm 36.99^{\mathrm{a}}$ & $64.67 \pm 1.26^{\mathrm{a}}$ & $2.78 \pm 0.06^{\mathrm{c}}$ & $8.24 \pm 0.12^{\mathrm{c}}$ \\
& $1^{\text {st }}$ day & $242.23 \pm 27.67^{\mathrm{a}}$ & $71.33 \pm 1.69^{\mathrm{a}}$ & $3.03 \pm 0.05^{\mathrm{b}}$ & $9.28 \pm 0.14^{\mathrm{b}}$ \\
& $3^{\text {rd }}$ day & $276.57 \pm 34.59^{\mathrm{a}}$ & $75.33 \pm 0.72^{\mathrm{a}}$ & $3.81 \pm 0.05^{\mathrm{a}}$ & $11.99 \pm 0.42^{\mathrm{a}}$ \\
\hline
\end{tabular}

Values are expressed as means \pm SE; Means within the same column carrying different letters are significantly different at ( $<<0.05)$

Table 3. The mean values of cortisol (ug/dL), total antioxidant capacity $(\mathrm{mM} / \mathrm{L})$, nitric oxide $(\mu \mathrm{mol} / \mathrm{mL})$ in control samples, Therapeutic Dose (TD) and Double Therapeutic Dose (DTD) groups

\begin{tabular}{lllll}
\hline & & Cortisol & TAC & NO \\
\hline Control & & $5.03 \pm 0.81^{\mathrm{b}}$ & $44.84 \pm 04.09^{\mathrm{a}}$ & $9.56 \pm 0.70^{\mathrm{c}}$ \\
TD & $1^{\text {st }}$ day & $8.95 \pm 1.03^{\mathrm{b}}$ & $21.85 \pm 4.06^{\mathrm{b}}$ & $18.98 \pm 4.46^{\mathrm{bc}}$ \\
& $3^{\text {rd }}$ day & $12.91 \pm 3.88^{\mathrm{b}}$ & $19.59 \pm 3.37^{\mathrm{bc}}$ & $20.42 \pm 3.79^{\mathrm{bc}}$ \\
DTD & $7^{\text {th }}$ day & $11.72 \pm 2.55^{\mathrm{b}}$ & $11.43 \pm 0.38^{\mathrm{cd}}$ & $23.74 \pm 6.24^{\mathrm{bc}}$ \\
& $1^{\text {st }}$ day & $14.57 \pm 3.96^{\mathrm{b}}$ & $16.63 \pm 3.51^{\mathrm{d}}$ & $29.04 \pm 9.14^{\mathrm{b}}$ \\
& $3^{\text {rd }}$ day & $26.35 \pm 6.59^{\mathrm{a}}$ & $9.87 \pm 0.9^{\mathrm{bcd}}$ & $32.87 \pm 7.02^{\mathrm{bc}}$ \\
& $7^{\text {th }}$ day & $35.97 \pm 2.79^{\mathrm{a}}$ & $0.62 \pm 0.25^{\mathrm{e}}$ & $52.32 \pm 6.76^{\mathrm{a}}$ \\
\hline
\end{tabular}

Values are expressed as means \pm SE; Means within the same column carrying different letters are significantly different at ( $<<0.05$ ) 
Table 4. The mean values of testosterone $(\mathrm{ng} / \mathrm{mL})$ and free testosterone $(\mathrm{pg} / \mathrm{mL})$ in control samples, Therapeutic Dose (TD) and Double Therapeutic Dose (DTD) groups

\begin{tabular}{llll}
\hline & & Testosterone & F. Testosterone \\
\hline Control & & $0.30 \pm 0.03^{\mathrm{c}}$ & $14.35 \pm 0.72^{\mathrm{d}}$ \\
TD & $1^{\text {st }}$ day & $0.43 \pm 0.01^{\mathrm{c}}$ & $32.63 \pm 0.86^{\mathrm{c}}$ \\
& $3^{\text {rd }}$ day & $0.47 \pm 0.07^{\mathrm{c}}$ & $43.00 \pm 0.77^{\mathrm{bc}}$ \\
& $7^{\text {th }}$ day & $1.24 \pm 0.04^{\mathrm{b}}$ & $50.33 \pm 0.67^{\mathrm{b}}$ \\
DTD & $1^{\text {st }}$ day & $2.70 \pm 0.43^{\mathrm{a}}$ & $44.65 \pm 3.05^{\mathrm{b}}$ \\
& $3^{\text {rd }}$ day & $2.74 \pm 0.04^{\mathrm{a}}$ & $92.86 \pm 1.15^{\mathrm{a}}$ \\
& $7^{\text {th }}$ day & $2.94 \pm 0.03^{\mathrm{a}}$ & $86.14 \pm 1.38^{\mathrm{a}}$ \\
\hline
\end{tabular}

Values are expressed as means \pm SE; Means within the same column carrying different letters are significantly different at $(\mathrm{p}<0.05)$

\section{DISCUSSION}

The obtained data revealed a significant increase in urea, uric and creatinine markers of renal function in both TD and DTD groups but this was obviously increased in DTD indicating the load of IVM medication on renal function. Transient non-significant renal disturbances, which suggest that IVM seems to cause minor damage to the glomeruli (Arise and Malomo, 2009). Reduced renal blood flow associated with higher serum urea concentration may impair the secretory function of the kidney. Malfunction in the glomerularfiltration results in the retention of substances including urea, uric acid and creatinine and this might be responsible for their high serum levels in the treated groups (Selvakumar et al., 2013).

ALT and AST are commonly measured clinically as a part of a diagnostic evaluation of hepatocellular injury, to determine liver health (Wang et al., 2012). The results of a current study indicating a significant increase in both enzyme activities in TD and DTD groups with highest increments in DTD group indicating the incidence of hepatic injuries due to IVM medication. These obvious increases of ALT and AST were confirmed by the study done by (Arise and Malomo, 2009). A marked effects on some liver function enzymes such as AST and ALT in therapeutic and double therapeutic doses of IVM in Wistar Albino rats (Ashang, 2009). The findings of raised enzymes following IVM administration, suggests that in liver disease the use of IVM must be done with caution (Hutchinson et al., 2009).

In DTD group, IVM induced a significant increase in LDH. This result was become in accordance with that stated by (Arise and Malomo, 2009). Creatine phosphokinase is an enzyme expressed by various tissues and cell types, especially skeletal muscle
(Parker et al., 2013). Our study represented an elevation in CPK enzyme activities in TD and DTD groups, nevertheless, it's more pronounced in the DTD that elevation indicate the happening of muscle injuries which might be induced by a significantly increased serum $\mathrm{T}_{3}$ and $\mathrm{T}_{4}$ which consequently accelerates the muscle protein degradations which accompanied by weight loss is the major clinical sign was observed due to the increased protein degradation by increased thyroid hormones (Mitrou et al., 2010).

The illustrated data in Table 3 showed a significant increase in serum cortisol levels at $3^{\text {rd }}$ and $7^{\text {th }}$ days after IVM injection in DTD group. Whilst, its increase in TD group and $1^{\text {st }}$ day in DTD groups were non-significant in relation to group one. Cortisol is a steroid hormone produced by the zona fasciculata of the adrenal cortex. Elevated levels of cortisol in IVM treated rabbits especially in DTD group is a clear indication of the stress condition of those animals (Marieb and Hoehn, 2010). In the context of oxidative stress induced by IVM injection a significant decrease in serum, TAC levels were recorded in a positive relationship to the experimental time in both TD and DTD groups. On the contrary, the levels of NO were significant gradually increased in them. A significant decrease in antioxidant status of New Zealand rabbits injected by IVM by a significant decrease in TAC and a significant increase of NO (Atakisi et al., 2009). These findings may suggest that IVM is a safe anti-parasitic drug for mammals but to less extent; it may have an effect on the balance between oxidants and antioxidants (El-Shenawy, 2010). IVM may produce free radicals and thus results in cytotoxic effect on the parasite. Nitric oxide is involved in various path physiological processes. It acts as free radicals and as host defense mechanisms through cytotoxic effect (Tamarozzi et al., 2011). IVM was reported to counteract against scabies agents by inducing free radicals associated damage and by decreasing antioxidant enzyme activity (Behera et al., 2011).

Testosterone is a steroid hormone from the androgen group in mammals, reptiles, birds and other vertebrates. In mammals, testosterone is primarily secreted in the testicles of males and the ovaries of females, although small amounts are also secreted by the adrenal glands (Vodo et al., 2013). Free testosterone is the serum testosterone that is not bound to Sex Hormone Binding Globulin (SHBG) or albumin. It is this free testosterone that is biologically active able to exert its effect by permeating a cell and activating its receptor (Kevin et al., 
2012). The obtained data in Table 4 revealed a significant increase in testosterone and free testosterone in both TD and DTD groups with a higher increase in DTD group that improve the male reproduction. This finding supports the argument that IVM induce a deleterious effect on female reproduction, which we suggest to be due to increased testosterone and free testosterone. This argument needs further investigation to determine the principle cause of female infertility due to IVM injection.

\section{CONCLUSION}

From the data of the current study on TD and DTD with lucid effects in DTD group. Therefore, we can conclude that:

- The therapeutic dose of IVM must be adjusted to prevent the overdose side effects

- IVM induced deleterious effects on renal and hepatic functions

- IVM induced muscle injuries due to the significantly increased $\mathrm{T}_{3}$ and $\mathrm{T}_{4}$ and monitored by the significant increase in $\mathrm{LDH}$ and $\mathrm{CPK}$

- IVM induced oxidative stress

- IVM induced the significant increases in testosterone and free testosterone, which directs us to investigate the effect of IVM on female as the argument of infertility in females due to IVM, may be referred to increased serum testosterone and free testosterone

- We recommend using a general tonic in the course of IVM medication

\section{REFERENCES}

Arise, R.O. and S.O. Malomo, 2009. Effects of ivermectin and albendazole on some liver and kidney function indices in rats. Afr. J. Biochem. Res., 3: 190-197.

Ashang, B.U., 2009. Effect of therapeutic and toxic doses of ivermectin (Mectizan) on total serum proteins and hepatic enzymes of wistar albino rats. Int. J. Biol. Chem., 3: 142-147. DOI: 10.3923/ijbc.2009.142.147

Atakisi, E., O. Atakisi, B. Topcu and M. Uzun, 2009. Effects of therapeutic dose of ivermectin on plasma nitric oxide and total antioxidant capacity in rabbits. Eur. Rev. Med. Pharmacol. Sci., 13: 425-429. PMID: 20085123

Awasthi, A., M. Razzak, R. Al-Kassas, H. Joanne and G. Sanjay, 2012. An overview on chemical derivatization and stability aspects of selected avermectin derivatives. Chem. Pharm. Bull., 60: 931-944. DOI: $10.1248 / \mathrm{cpb} . c 12-00258$
Behera, S.K., U. Dimri, S.K. Singh and R.K. Mohanta, 2011. The curative and antioxidative efficiency of ivermectin and ivermectin + vitamin E-selenium treatment on canine Sarcoptes scabiei infestation. Vet. Res. Commun., 35: 237-244. DOI: 10.1007/s11259-011-9468-8

Chaccour, C.J., K.C. Kobylinski, Q. Bassat, T. Bousema and C. Drakeley et al., 2013. Ivermectin to reduce malaria transmission: A research agenda for a promising new tool for elimination. Malaria J., 12:153-161. DOI: 10.1186/1475-2875-12-153

El-Shenawy, N.S., 2010. Effects of insecticides fenitrothion, endosulfan and abamectin on antioxidant parameters of isolated rat hepatocytes. Toxicol. Vitro, 24: 1148-1157. PMID: 20214973

Epstein, S.E. and S.R. Hollingsworth, 2013. Ivermectininduced blindness treated with intravenous lipid therapy in a dog. J. Vet. Emerg Crit. Care (San Antonio), 23: 58-62. PMID: 23317101.

Giannetti, L., A. Giorgi, F. Necci, G. Ferretti and F. Buiarelli et al., 2011. Validation study on avermectine residues in foodstuffs. Anal. Chim. Acta, 700: 11-15. DOI: 10.1016/j.aca.2010.12.035

Godara, R., R.L. Sharma and S.S. Sodhi, 2011. Efficacy of fenbendazole, levamisole and ivermectin against gastrointestinal nematodes in Jamunapari goats. J. Parasit. Dials, 35: 219-221. DOI: 10.1007/s12639011-0052-5

Hutchinson, G.W., K. Dawson, C.C. Fitzgibbon, P.J. Martin, 2009. Efficacy of an injectable combination anthelmintic (nitroxynil+clorsulon+ivermectin) against early immature Fasciola hepatica compared to triclabendazole combination flukicides given orally or topically to cattle. Vet. Parasitol., 162: 278284. PMID: 19375232

Kevin, M., D.O. Pantalone and C.C.D. Ecnu, 2012. Male hypogonadism: More than just a low testosterone. Cleveland Clin. J. Med., 79: 717-725. DOI: 10.3949/ccjm.79a.11174

Lumaret, J.P., E. Faiek, F. Kevin, R. Jörg and W. Keith, 2012. A review on the toxicity and non-target effects of macrocyclic lactones in terrestrial and aquatic environments. Current Pharmaceut. Biotechnol., 13: 1004-1060. DOI: 10.2174/138920112800399257

Marieb, E.N. and K. Hoehn, 2010. Human Anatomy and Physiology. 8th Edn., Benjamin Cummings, San Francisco, ISBN-10: 0321543122, pp: 1229.

Mitrou, P., S.A. Raptis and G. Dimitriadis, 2010. Insulin action in hyperthyroidism: A focus on muscle and adipose tissue. Endocrine Rev., 31: 663-679. DOI: 10.1210/er.2009-0046 
Parker, B.A., J.A. Capizzi, A.S. Grimaldi, P.M. Clarkson and S.M. Cole et al., 2013. Effect of Statins on Skeletal Muscle Function. Circulation, 127: 96-103. DOI: 10.1161/CIRCULATIONAHA.112.136101

Selvakumar, K., S. Bavithra, S. Suganya, F.A. Bhat and G. Krishnamoorthy et al., 2013. Effect of quercetin on haematobiochemical and histological changes in the liver of polychlorined biphenyls-induced adult male wistar rats. J. Biomarkers, 2013: 960125960136. DOI: 10.1155/2013/960125

Suarez, G., L. Alvarez, D. Castells, O. Correa and P. Fagiolino et al., 2013. Relative bioavailability and comparative clinical efficacy of different ivermectin oral formulations in lambs. BMC Vet. Res., 9: 27. DOI: 10.1186/1746-6148-9-27

Tamarozzi, F., A. Halliday, K. Gentil, A. Hoerauf and E. Pearlman et al., 2011. Onchocerciasis: the Role of Wolbachia bacterial endosymbionts in parasite biology, disease pathogenesis and treatment. Clin. Microbiol. Rev., 24: 459-468. DOI: 10.1128/CMR.00057-10
Trailovic, S.M. and J.T. Nedeljkovic, 2011. Central and peripheral neurotoxic effects of ivermectin in rats. J. Vet. Med. Sci., 73: 591-599. DOI: 10.1292/jvms.100424

Vodo, S., N. Bechi, A. Petroni, C. Muscoli and A.M. Aloisi, 2013. Testosterone-induced effects on lipids and inflammation. Mediators Inflammat., 2013: 183041-183048. DOI: 10.1155/2013/183041

Wang, C.S., T.T. Chang, W.J. Yao, S.T. Wang and P. Chou, 2012. Impact of increasing alanine aminotransferase levels within normal range on incident diabetes. J. Formos. Med. Assoc., 111: 201208. DOI: 10.1016/j.jfma.2011.04.004

Yovany, M., F.N. Joseph, S. Jonathan, D.M. Charles and G.G. Timothy, 2010. Ivermectin disrupts the function of the excretory-secretory apparatus in microfilariae of Brugia malayi. PNAS, 107: 2012020125. DOI: 10.1073/pnas. 1011983107 